\title{
Frontiers
}

\section{in the Psychotherapy} of Trauma \& Dissociation

\section{Cross-Cultural Trauma Work With a Tribal Missionary: A Case Study Heather Davediuk Gingrich}

The Official Clinical Journal of the International Society for the Study of Trauma and Dissociation 


\section{Frontiers in the Psychotherapy of Trauma \& Dissociation}

The Official Clinical Journal of the ISSTD

\section{EDITORS}

A. STEVEN FRANKEL, Ph.D., J.D., Clinical Professor of Psychology, University of Southern California, Los Angeles, California, USA

ANDREAS LADDIS, M.D., Private Practice and Faculty, Boston University, School of Public Health, Boston, Massachusetts, USA

\section{ASSOCIATE EDITOR}

MARTIN J. DORAHY, Ph.D., Professor, Department of Psychology, University of Canterbury, Christchurch, New Zealand and The Cannan Institute, Brisbane, Australia

Frontiers in the Psychotherapy of Trauma E Dissociation is published by the International Society for the Study of Trauma and Dissociation, Inc., 8400 Westpark Drive, 2nd Floor, McLean, Virginia, 22102, USA.

\section{Annual Subscription, Volume 2, 2018}

Online subscription is part of the membership dues of the International Society for the Study of Trauma and Dissociation. Visit http://www.isst-d.org/default.asp?contentID=44.

Production and Advertising Office: ISSTD Headquarters, 8400 Westpark Drive, 2nd Floor, McLean, Virginia, 22102. Attention: Thérèse O. Clemens, CAE, Managing Editor.

Copyright $(2018$ International Society for the Study of Trauma and Dissociation. All rights reserved. No part of this publication may be reproduced, stored, transmitted, or disseminated in any for or by any means without prior written permission from the International Society for the Study of Trauma and Dissociation. The publisher assumes no responsibility for any statements of fact or opinion expressed in the published papers. The appearance of advertising in this journal does not constitute an endorsement or approval by the publisher, the editor, the editorial board, or the board of directors of the International Society for the Study of Trauma and Dissociation of the quality or value of the product advertised or of the claims made of it by its manufacturer.

Subscriptions to this journal are acquired through membership in the International Society for the Study of Trauma and Dissociation only.

Visit http:/ / www.isst-d.org/default.asp?contentID=45.

Permissions. For further information, please write to info@isst-d.org.

\section{EDITORIAL BOARD}

ELIZABETH S. BOWMAN, M.D., Editor Emerita, Journal of Trauma \& Dissociation, Adjunct Professor of Neurology, Indiana University School of Medicine, Indianapolis, Indiana, USA

LAURA S. BROWN, Ph.D., Private Practice, Seattle, Washington, USA

RICHARD A. CHEFETZ, M.D., Private Practice, Faculty and Founding Member Institute of Contemporary Psychotherapy \& Psychoanalysis, Distinguished Visiting Lecturer: William Alanson White Institute of Psychiatry, Psychoanalysis \& Psychology, New York City, USA

CONSTANCE J. DALENBERG, Ph.D., Trauma Research Institute, California School of Professional Psychology, San Diego, California, USA

J.K. JUDITH DANIELS, Ph.D., Faculty of Behavioural and Social Sciences, University of Groningen, The Netherlands

STEVEN N. GOLD, Ph.D., Professor, Center for Psychological Studies, and Founding Director, Trauma Resolution E Integration Program, Nova Southeastern University, Fort Lauderdale, Florida, USA

ELIZABETH B. HEGEMAN, Ph.D., Professor, Department of Anthropology, John Jay College of Criminal Justice, New York, New York, USA 
RICHARD P. KLUFT, M.D., Ph.D., Private Practice and Clinical Professor of Psychiatry, Temple University School of Medicine; Faculty Member, Philadelphia Center for Psychoanalysis, Philadelphia, Pennsylvania, USA

CHRISTA KRÜGER, M.D., Professor of Psychiatry, University of Pretoria, Pretoria, Gauteng, South Africa

KARLEN LYONS-RUTH, Ph.D., Professor of Psychology, Harvard Medical School, Cambridge, Massachusetts, USA

ALFONSO MARTÍNEZ-TABOAS, Ph.D., Professor, Albizu University, San Juan, Puerto Rico WARWICK MIDDLETON, M.D., Adjunct Professor, Cannan Institute, Brisbane, Australia ELLERT R. S. NIJENHUIS, Ph.D., Department of Psychiatry and Outpatient Department Mental Health Care Drenthe, Assen, The Netherlands

SANDRA PAULSEN, Ph.D., Bainbridge Institute for Integrative Psychology, Bainbridge Island, Washington, USA

VEDAT ŞAR, M.D., Professor of Psychiatry, Koç University School of Medicine (KUSOM), Istanbul, Turkey

JOYANNA SILBERG, Ph.D., Trauma Disorders Program, Sheppard Pratt Health Systems, Baltimore, Maryland, USA

KATHY STEELE, M.N., C.S., Private Practice, Atlanta, Georgia, USA

ONNO VAN DER HART, Ph.D., Emeritus Professor of Psychopathology of Chronic Traumatization, Department of Clinical and Health Psychology, Utrecht University, Utrecht, The Netherlands

VICTOR WELZANT, PSY.D., Sheppard Pratt Health Systems, Trauma Disorders Program

\section{REVIEWERS}

JOHN BRIERE, Ph.D., Associate Professor of Psychiatry and Psychology, University of Southern California Keck School of Medicine, Los Angeles, California, USA

SHELDON IZKOWITZ, Ph.D., Clinical Associate Professor of Psychology and Clinical Consultant, Postdoctoral Program, New York University, New York City, USA and Teaching Faculty \& Supervisor of Psychotherapy and Psychoanalysis, National Institute for Psychotherapies, New York City, USA

MARY-ANNE KATE, Ph.D. CANDIDATE, Researcher at University of New England, Australia; University of New England, New South Wales, Australia

ULRICH F. LANIUS, Ph.D., Private Practice, West Vancouver, British Columbia, Canada

\section{SUPPORTERS}

ISSTD thanks its generous supporters whose contributions have made this publication possible:

Andreas Laddis, M.D., USA

\section{The}

\section{Cannan}

\section{Institute}

Cannan Institute, Australia

Warwick Middleton, M.D., Australia

Dana Ross, M.D., Canada

Martin J. Dorahy, Ph.D., New Zealand

Kate McMaugh, Australia

Sara Y. Krakauer, USA 


\title{
ARTICLE
}

\section{Cross-Cultural Trauma Work With a Tribal Missionary: A Case Study}

\author{
HEATHER DAVEDIUK GINGRICH ${ }^{1}$
}

Denver Seminary

\begin{abstract}
This case study describes cross-cultural trauma therapy conducted in a context of multiple cultural and religious complexities. The clinician, a Caucasian Canadian missionary taught and practiced for a number of years in the huge urban metropolis of Manila, in the Philippines, where the majority of the population are Roman Catholic. Her client was a member of an indigenous tribe in a different Asian country, who was assigned as a missionary to a remote rural, Muslim village. While therapist and client shared their Protestant, Christian faith and their identity as missionaries, ethnically and culturally there were vast differences between them. While they were both foreigners living in the Philippines, they worked in very different parts of the country which had dissimilar cultures. The article highlights some of the unique aspects of this case, giving context and rationale for specific interventions aimed at containing posttraumatic symptoms and processing the client's trauma. The cultural dynamics and use of religion and spirituality within the therapeutic work are given particular focus.
\end{abstract}

\footnotetext{
${ }^{1}$ Author Note: Heather Davediuk Gingrich, Ph.D. is Professor of Counseling at Denver Seminary. Two and a half years as a child in Pakistan, her experiences of counseling, teaching, studying, and conducting research for eight years in the Philippines, as well as her current situation as a Canadian who is living in the United States, have created an interest in multicultural issues, including cross-cultural trauma counseling. She is author of Restoring the Shattered Self, A Christian Counselor's Guide to Complex Trauma, co-editor (with her husband, Fred) and author of several chapters in Treating Trauma in Christian Counseling, as well as co-author of a counseling skills book, various chapters in other books, and numbers of journal articles.

Correspondence can be addressed to Heather Davediuk Gingrich at heather.gingrich @denverseminary.edu or Heather Davediuk Gingrich, Professor of Counseling, Denver Seminary, Littleton, Colorado, USA
} 
KEYWORDS trauma,cross-cultural therapy, religion and spirituality in therapy

I was living in the Philippines, teaching in masters and doctoral level counseling programs affiliated with a conservative, Protestant Christian seminary, when I began working with Ahmee. Ahmee was a 35-year-old single woman from an indigenous tribe in another Asian country, who also identified as a conservative, Protestant Christian. Unlike the huge metropolis of Manila in which I lived and worked, which was populated largely by Roman Catholics, Ahmee had been living and working in a remote Muslim village in the southern Philippines where there has been political and religious unrest for decades. Therefore, while we were both missionaries and foreigners living and working in the Philippines, we were in different areas of the country, living under vastly different circumstances, among people who were Filipino but whose cultures differed greatly from each other.

Ahmee was referred to me by the director of an international mission organization. He related that Ahmee, one of their affiliated missionaries, had witnessed a terrorist, execution-style murder the week before, and had just arrived in Manila from the island where she was stationed. Their institutional policy was that any of their personnel who witness violence, or who are otherwise victimized, are required to have a professional psychotherapeutic assessment and ongoing treatment as needed. As their in-house counselors were temporarily out of the country, he asked if I would be available for this purpose.

Although I was willing to see Ahmee, I had a number of concerns. I had previously worked extensively with victims of trauma, but my areas of expertise were complex trauma and dissociative disorders, so working with single-incident, adult-onset trauma was relatively new to me. Another complication was the myriad of cultural issues imbedded in the case as I, a Canadian Caucasian living in the Philippines, worked with an Asian missionary from a country I knew nothing about and for whom English is a second language. To add further to the cultural complexities, Ahmee was working among a distinct tribal group within the Philippines whose culture I was unfamiliar. The fact that the potentially traumatic event was so recent, the ongoing danger inherent in Ahmee's ministry situation, the time constraints under which the therapy could be conducted, and the limited professional resources available, all added to the challenges of this case. The therapy took place in 11 sessions and spanned six months, three months of which Ahmee spent back in the tribal village. Specifically, we would have two or three sessions within a several-week period, with a break of 6-10 weeks when Ahmee was back living in her ministry location.

In presenting this case study, I will attempt to highlight some of the unique aspects of the case, giving context and my rationale for intervening 
in specific ways. The cultural dynamics and use of spirituality within the therapeutic work will be given particular focus.

\section{INITIAL INTERVENTIONS}

In this section I will discuss the issues around assessment and dealing with affect. While Ahmee initially presented as emotionally blunted, she soon exhibited intrusive posttraumatic symptoms making appropriate affective containment essential.

\section{Assessment}

I was accustomed to conducting long-term counseling where I could take some time to gather background information, including a trauma history. But this was not an adult survivor of childhood trauma who was entering therapy because of intrusive posttraumatic or debilitating dissociative symptoms. I knew from the director of Ahmee's mission that the murder she had witnessed occurred only days previously and that I would not likely have the luxury of a lot of time with her. So rather than conducting a formal assessment, I chose to focus on establishing the therapeutic relationship, allowing Ahmee to tell her story, and thereby make an informal clinical assessment of the extent to which witnessing the violent murder of her friend had impacted her.

\section{Accessing Affect}

Ahmee was eager to pour out her experiences to a listening ear, and rapport was quickly established. In the first session she talked in detail about being mere feet away when a gunman shot and killed the Filipina friend she was with. Initially it appeared to Ahmee that the gunman was after her. Even though that turned out not to be the case, Ahmee's immediate over-riding concern was that she herself would be the next target.

It struck me that while Ahmee described horrific scenes and used emotion-laden words, her body looked relaxed and she spoke calmly. A few occasional tears were the only indication that Ahmee was actually experiencing any affect. Her verbalized impatience to get back to the tribe also seemed premature given the continued political unrest in the area and what she had so recently been through. As it is not considered culturally appropriate to show emotion in many Asian countries (Rothbaum, Morelli, Pott, \& Liu-Constant, 2000), I knew I had to consider the possibility that this was a cultural phenomenon. Nonetheless, Ahmee's behavior was similar to that of many complex trauma survivors I had previously worked with whose affect had become dissociated from the rest of their experience (see BASK Model of Dissociation, Braun, 1988). 
If this had not been a crisis situation, I would have broached the topic of our cultural differences directly (Day-Vines et al., 2007), asking specifically about cultural values with respect to showing emotion, dealing with trauma, and grieving. But I chose, instead, to assign some bibliotherapy on the topic of emotions and asked her to keep a therapy journal in light of my hypothesis that what I was seeing was more than simply a cultural artifact. I knew that I could delve more deeply into any potential cultural issues later on if necessary.

\section{Affect Regulation and Symptom Management}

The next week Ahmee came into the session describing intrusive PTSD symptoms of flashbacks and nightmares accompanied by overwhelmingly intense feelings. In contrast to the blunted affect she exhibited in our initial interview, in this session she cried, showed facial expressions of terror, and was physically agitated. Whether or not Ahmee's lack of expressed emotion the week before had a cultural component no longer seemed relevant; I deemed that the immediate task was to help Ahmee strike a balance between continuing to experience and express her feelings so that she did not totally shut down again, while not being too overwhelmed by them. Teaching Ahmee mindfulness techniques (Koerner, \& Linehan, 2012) could have been helpful in this regard, but at the time mindfulness was not a concept that was as widely known or used as it is currently. However, I did normalize her reactions, giving Ahmee permission to acknowledge, re-experience and express her feelings.

During our first session Ahmee had conveyed impatience at being in Manila. Ahmee appreciated her director's concern for her, so she had come willingly to the session, but she had been hoping that I would give her a clean bill of health so that she could get right back to her work in the tribe. She now, however, realized that she needed some time to recover before returning to the tribe, although she felt guilty, thinking that she was abandoning her friends in the tribe. I affirmed that it was to be expected that survivors of trauma need time to heal and that this did not reflect negatively upon her sense of call and commitment to her ministry.

As Ahmee was now clearly exhibiting symptoms of PTSD, I determined that prolonged exposure therapy would be a helpful way to begin (Foa, Hembree, \& Rothbaum, 2007). She had already made a start by verbalizing her trauma narrative to me, this time including the formerly dissociated affective components. In order to expedite the process, I suggested that Ahmee share her experiences with any support person who would willingly listen, talk into a recording device when no one else was available, and continue to journal. It became apparent that Ahmee's fear was at times overwhelming. Before Ahmee left the second session, we rehearsed some relaxation techniques which she agreed to attempt on her own when her anxiety felt unmanageable. This is consistent with the idea of operating 
within the window of tolerance (Siegel, 1999); I hoped that the homework assignments I gave Ahmee would help her process her trauma but realized that if her affective level got too high it would be counterproductive.

Ahmee was an exceptionally well-motivated client. She did everything I suggested, spending many hours debriefing with support people and journaling. However, she also initiated other activities between sessions about which she would report back to me. For example, Ahmee spent a number of days in personal, spiritual retreat at a beautiful location, where she told me that she talked with God about what she was going through. Ahmee experienced this as a time of healing resulting in an increased sense of peace and knowledge of God's acceptance of her, despite her current struggles.

While her daytime intrusive symptoms had greatly diminished and she was making good use of the relaxation techniques, Ahmee was still having difficulty with nightmares. Not only were the horrors of her recent experience being replayed in her dreams, but as often happens with trauma, her current trauma opened the door to a previously experienced, but unresolved traumatic event. When Ahmee was a teenager, a Western missionary had died in her arms in a remote area of her home country, without anyone else around to help. Both the recent and past trauma were being relived while she was sleeping. I realized that processing this former trauma could be important, but it was essential for the trauma processing to be appropriately paced; there was too much traumatic material contained in the nightmares to process all of it immediately. I chose, therefore, to concentrate on symptom stabilization, focusing my intervention on how to temporarily alleviate the nightmares so that we could gradually process the material.

In my work with dissociative clients, including both those with dissociative identity disorder (DID) as well as other complex trauma survivors, I have found that nightmares, along with other symptoms, can be temporarily controlled through contracting with the whole personality system (Gingrich, 2013). While the contracting is between dissociated identities with trauma survivors who have DID, similar approaches can be used with the self-states or ego states of other clients (Noricks, 2011; Pressley \& Spinazzola, 2015; Shapiro, 2016). I have also discovered that, true to psychanalytic theory (Freud, 1950), nightmares are sometimes a way of difficult affective material bypassing conscious awareness in an attempt to draw attention to material that needs to be processed. As I had already observed that Ahmee was able to dissociate her affective experience, I hypothesized that Ahmee might be dissociative enough that a similar technique could be helpful in this situation.

Therefore, I explained to Ahmee that at some level, some part of her had control over what she dreamed, and I asked if the "part of her" that was allowing the nightmares to be experienced would agree to temporarily withhold them in favor of revealing the necessary content, at a workable 
pace. The "rest of Ahmee" would uphold their end of the deal by agreeing to be open to "listening" and willing, at a mutually agreed-upon time in the future, to process in therapy any content that came up through these alternative routes. The technique was successful with Ahmee. The nightmares immediately stopped, and only reoccurred, with different content, much later in therapy, subsequent to Ahmee experiencing further trauma in the months we worked together. Fulfilling her end of the bargain, Ahmee continued to work hard in-session and between sessions, gradually processing more aspects of her trauma.

I believe that making use of Ahmee's ability to dissociate resulted in the immediate, temporary containment of her nightmares. On the other hand, I see two reasons why the nightmares did not reoccur in the future: (1) Ahmee's willingness to process the traumatic content for some of her nightmares, and (2) her ability to resolve some current issues underlying her nightmares without further processing the old content. For example, dealing with the current fear of her own death, as described later, resolved Ahmee's powerlessness in an old event that she relived in the nightmares (holding in her arms a dying missionary woman).

\section{SURVIVING THE WAR ZONE}

Ahmee's goal was to become psychologically and emotionally ready to go back to the tribe. However, with the ongoing political instability of the area, involving possibilities of attacks and kidnappings by rebels, Ahmee was preparing to return to a war zone. Crisis situations, by nature of their destabilizing psychological effects, can often provide opportunities for change in other areas of life (Presbury, Echterling, \& McKee, 2001). In Ahmee's case, I believed that in order for her to be able to cope well in such dangerous circumstances, she needed to not only process her reactions to the trauma she had experienced, but also discover what changes, even if minor ones, were possible in a context where so much was out of her hands. Examples of helping Ahmee gain some sense of control over her life are discussed below according to theme rather than chronology.

\section{Setting Boundaries}

It became clear to me that Ahmee could effect changes that would greatly lower her overall stress level in the village. She had been available to the villagers day and night, dispensing medications and giving first aid, which meant that her sleep was usually interrupted, sometimes multiple times a night, resulting in ongoing physical fatigue. While there were genuine medical emergencies, she was often roused by a knock on the door for minor issues such as a request for aspirin due to a hangover, or a bandage for a superficial wound that could have waited until morning. Cultural issues 
played a part in this pattern consisting of both a "missionary" mentality that defined love and service as self-sacrificial giving, as well as the tribal culture that assumed that someone in need be given immediate aid. Ahmee realized that she could not survive under these conditions indefinitely and upon reflection came up with some ways she could set boundaries while minimizing cultural offensiveness.

Upon her return to the village two months after the shooting, Ahmee was able to make use of her position as "adopted daughter" of the religious head of the village to get the rest and privacy she needed. On Ahmee's behalf, this leader informed the villagers that Ahmee was not to be disturbed at night except in cases he deemed dire emergencies. He also invited Ahmee to sleep in his family's house rather than her own. The adopted family thus began to serve as a buffer between Ahmee and the village population at large.

Ahmee also began to recognize the importance of setting boundaries with members of her mission organization. Formerly, she had acquiesced to the demands of other members of her missionary team, despite the resulting detrimental personal effects. The couple she worked with rationalized the additional burden of responsibilities they placed on Ahmee by saying that she was not married with children as they were, which left her with more time. In reality, without the support and help of a spouse, Ahmee was burning out. Through our work together she became aware that as a unique person with her own personality style and specific needs, she had to set appropriate boundaries and accept responsibility for her own self-care. In some instances, Ahmee needed to be able to recognize co-workers' attempts to manipulate her through spiritualizing their requests (e.g., "If you truly had the heart of a servant that Christ desires of his children, Ahmee, you'd be willing to take this on...").

Due to the possibility that the director of Ahmee's mission agency and I could end up working at cross-purposes around some issues, I obtained Ahmee's consent to dialogue with him about her needs and the process of therapy. Fortunately, he was open to adjusting his expectations of her out of genuine concern for her healing and well-being, resulting in a sense of partnership together. One of the adjustments he made in consultation with Ahmee and me, was to bring Ahmee out of the village more frequently (i.e., three weeks in the village and a week in Manila rather than staying in the village for months at a time) so that she could have some rest and relaxation, and increased opportunities for support, debriefing, and therapy. Ahmee also learned to develop appropriate boundaries with the numerous Filipino churches that had committed to pray for Ahmee and her work in the village. Church members pressured her to visit them regularly, not realizing that in their attempts to show interest in her work; they were actually creating additional stress. Ahmee, appreciating their concern and feeling indebted to them, had felt obligated to acquiesce to their demands. 


\section{Safety Issues}

Although there was a constant level of physical danger in the village, Ahmee could enhance her safety to some extent by not going anywhere alone, not traveling at night or between villages unnecessarily, and by seeking refuge with her adopted family when at particular risk. Previously, she had lived as though oblivious to the potential dangers; dissociating her affect allowed her to ignore these realities. We worked on walking the fine line between dissociating enough to be able to function when she was in the village, but not dissociating to the extent that she was unaware of danger.

At one point, Ahmee received a death threat. With the help of other villagers, Ahmee was able to trace the source of the threat, and found an indirect, culturally acceptable way to make her would-be assassin aware of her knowledge. While the death threat and other events eventually led to the mission director's decision to take her out of an increasingly hazardous situation, before departing, Ahmee was able to offer a public hand of friendship to the man everyone knew had threatened her. As most of the villagers did not want Ahmee to leave, and were very upset at what had happened, Ahmee's gesture allowed the villagers a peaceful closure to the incident, as well as increasing the likelihood of Ahmee being wholeheartedly welcomed back to the village upon her hoped-for future return. The full impact of those stressful days hit Ahmee once she was safely back in Manila, so she had some processing to do. She did this willingly, and I saw growth in Ahmee's ability to cope with her feelings without dissociating.

I have not conducted therapy with war veterans, but I was aware of the similarities between working with Ahmee, and what it must be like for a clinician to work with military personnel who have been traumatized, but where developing readiness for redeployment is the goal. I must admit that before her eventual evacuation, everything in me wanted to keep Ahmee from going back to the village. I had to remind myself that it was ultimately Ahmee's and her mission director's decision to make. She had spent years learning the language, working among, and coming to love these villagers and felt she was doing so out of a sense of obedience to God. I had to keep my countertransference reactions in check.

\section{Role of Religion and Spirituality}

Recent research findings have shown that spirituality can play an important role in therapy, including trauma therapy (Walker, Courtois, \& Aten, 2015; see also the extensive annotated bibliography on religion, spirituality and trauma in the appendix of Gingrich \& Gingrich, 2017). The Association of Spiritual, Ethical, and Religious Values in Counseling (ASERVIC), a division of the American Counseling Association, considers incorporation of 
religion and spirituality into clinical work essential. They have published a set of spiritual and religious competencies that include, among others, using in therapy "spiritual and/or religious concepts that are consistent with the client's spiritual and/or religious perspectives and that are acceptable to the client" (Competency \#8, ASERVIC, 2009). Although the American Psychological Association (APA) has not published specific guidelines, provisional, research-based competencies have been proposed that are currently under discussion (Vietein \& Scammell, 2015; Vietein et al., 2013). The APA has, however, published a number of books on religion, spirituality, and psychotherapy (e.g., Aten \& Leach, 2009; Miller, 1999; Plante, 2009; Walker et al., 2015), and the journal of APA Division 36, Psychology of Religion and Spirituality addresses such issues. An extensive literature review (Harris, Randolph, \& Gordon, 2016), which examined the expectations and preferences of clients for having spirituality addressed in their therapy, revealed the following factors: client magnitude of spiritual beliefs, client gender, the match between the client and counselor's beliefs and values, type of therapy, and counselor openness to spiritual issues.

There is much discussion in the literature on psychology of religion about whether the terms religion and spirituality are the same construct or differ in significant ways. While there is not full consensus, authors generally agree that while the overlap is significant, spirituality is usually regarded as the more general term, with religion being a subcategory. In this view, not everyone would consider themselves religious, but even nonreligious individuals would hold some things sacred, have a sense of the transcendent, or view themselves and others as spiritual beings. In this sense, all psychotherapists, whether self-identified as religious or secular, are dealing with the spiritual aspects of our clients any time we are touching on topics related to life purpose, meaning, intimacy, and so on (see Hill \& Pargament, 2008; Hill et al., 2000; Young \& Cashwell, 2011).

The challenge for clinicians is to be able to understand the nature and importance of our clients' religious and/or spiritual views and respect them, while not imposing our own views (Vieten \& Scammell, 2015). Adding to the complexities is that there can be both healthy and dysfunctional aspects to any individual's belief system (Plante, 2009). The key to working with spirituality therapeutically is to be able to tease out the healthy and unhealthy aspects, use the positive aspects as potentially important resources, and appropriately confront what appears to be causing damage (Pargament, 2007). This is tricky, both because of the sensitivity clients may have around their spirituality (Walker, McGregor, Quagliana, Stephens, \& Knodel, 2015), as well as our own vulnerabilities around religious issues which can show up as strong countertransference reactions (Wiggins, 2009). 


\section{Shared Spirituality: An Asset}

Aimee's spirituality was core to her very being. Her sense of personal relationship to God not only was the motivating factor behind her missionary service, but it impacted her day-to-day decisions. I could identify. Although I did not live in the dangerous, primitive conditions that Ahmee did, my motivation for putting up with the many adjustments and stressors resulting from living and working cross-culturally was similar. Both Ahmee and I felt that God had led us to our places of cross-cultural ministry, and that this sense of calling was the key factor in keeping us there, despite the difficulties.

Although appropriate use of explicitly religious interventions requires great care, even when client and therapist come from similar religious traditions, when used thoughtfully, and always with a view as to what the therapeutic impact might be, they can be of great benefit (Brownell, 2015; McMinn, 1996). I believe that the religious values that Ahmee and I held in common were of great benefit to my work with her. They allowed me to be more easily attuned to where an aspect of Ahmee's spirituality could be used as a resource which, in turn, gave Ahmee permission to bring up topics with spiritual content. I think that the religious convictions we shared were also a significant factor in the quick formation and strength of the therapeutic alliance. Following are some specific examples of how spirituality was core to my work with Ahmee.

\section{God is in Control}

In preparation for Ahmee to go back to the village for the first time after the murder, I did some modified systematic desensitization exercises with her, combining visualization and relaxation with discussions of practical ways to minimize the legitimate risks to her safety. We had both assumed that the aspect of the trip which would be the most anxiety-producing would be going past the area where the shooting had occurred. However, as she visualized the final leg of the journey, which involved being in a small outrigger boat for several hours in open sea, she flashed back to an incident several years before where she had almost drowned taking this same boat ride. She described how a storm had unexpectedly arisen, blowing the overloaded boat off course and almost capsizing it. Fearing for their lives, passengers were screaming and praying. Miraculously, they rode out the storm, but the memory of this incident was indelibly etched on Ahmee's mind with blatant terror showing on her face as she relived the incident.

While I knew that Ahmee needed to process this particular memory, my dilemma was how to help her prepare to get on the boat again when the same thing could possibly happen! Such boats are frequently filled to over their capacity, and many people die each year when they overturn. Yet, 
it was the sole means of transportation by which Ahmee could get to the island where the village was located.

One of the ways in which my own spirituality impacts how I do therapy is that I pray for my clients, both outside of session, and silently within session. Of course, within session my main focus is listening to my clients, so my prayers in this context tend to be brief appeals such as "Help me God!" This is the type of prayer I was utilizing during this particular session. I was at a loss as to how to intervene. Ahmee's fear was not irrational; there was very real peril involved, so a cognitive-behavioral-therapy-type approach was not an obvious choice.

As the session went on, I was reminded of the vocal accompaniment track I happened to have in my office because I was preparing to sing a solo in an upcoming chapel service. The impression that I should sing it for Ahmee would not go away despite my internal protests that singing to a client is not part of evidence-based practice! There is literature on appropriate use of spiritual interventions in therapy (see Chapter 15 in Sbanotto, Gingrich, \& Gingrich, 2016, pp. 297-320 for a summary), however, while the literature does not specifically address singing, my decision to seek permission from Ahmee to do so fit within the general guidelines discussed in the literature. Therefore, with Ahmee's consent I sang her a song entitled "God is in Control," which includes in the lyrics lines such as, "We believe that His children will not be forsaken," and "This is no time for fear, this is a time for faith and determination." My risk paid off since Ahmee repeatedly thanked me for singing the song, and the following week reported that the words "God is in control" played over and over in her mind all week having a significant, positive impact on her. Ahmee's reaction was not a naïve, simplistic sense that "God won't let anything bad happen to me" because she knew that her relationship with God did not guarantee her safety. However, her sense of increased peace was more related to the idea that God was in control of the big picture, whether or not she survived the boat ride. Several months later Ahmee was again caught in a storm while at sea, but she did not panic, in fact quite the opposite. Ahmee was instrumental in calming down the other passengers thereby preventing the hysteria that could otherwise have resulted in the boat sinking.

\section{Death is Not the End}

Although nightmares had not been a problem since near the beginning of therapy, several months later Ahmee began to describe some nightmares of a different nature. One was particularly vivid, no doubt spurred on by the death threat she had received. In it she was attacked and ultimately killed by a man wielding a machete. The observing ego in her dream felt a sense of resignation at viewing her dead body.

Again, I prayed silently for guidance about the most appropriate way to process this particular dream; what came to mind was inner healing 
prayer (e.g., Garzon \& Burkett, 2002; Hunter, 2009). Inner healing prayer is generally performed by lay people as a spiritual alternative to healing emotional wounds through therapy. While specific approaches may differ in the details, they all involve going back to a past, hurtful event, and in some way inviting Jesus to bring healing from that emotional wound (Hurding, 1995). I have seen casualties of such approaches, usually in regard to trauma being opened up and the facilitators not knowing how to contain intrusive posttraumatic symptoms at the end of the prayer session. However, on a few occasions, I have used such techniques in the context of therapy and have found them to be helpful with particular clients who have great faith in the power of prayer and believe that God is the ultimate source of healing.

I knew Ahmee fit into this category, so after explaining the process and obtaining her consent, I used a specific form of inner healing prayer developed by a well-respected Christian psychologist (Tan, 1992). I asked Ahmee to once more narrate her dream, while we invited Jesus to "minister His presence" to Ahmee. This time, instead of seeing her dead corpse, she had a dramatic vision of her resurrected body, that is, the heavenly, eternal body many Christians believe they will receive after death. This revelation had a profound impact on Ahmee. She had long believed that life is not over when the earthly body dies. However, after "seeing" her heavenly body, the reality of the everlasting life that was a central belief of her religious tradition was able to penetrate in a way it never had before.

Only upon seeing the extent of the relief Ahmee experienced through healing prayer did I fully realize how much of a core issue fear of death had been for her. The memory of the Christian worker dying in her arms, recollections of being at the deathbeds of numerous friends and family members, terror of drowning during a boat trip, and fear of being targeted for assassination all were connected to this existential theme. Once Ahmee identified anxiety around nonexistence as her fundamental concern, accepted the eventuality of her own earthly death, and integrated the affective component with her cognitive belief in an afterlife, the nightmares ceased, and she felt enormous peace at facing whatever the future might hold.

\section{Forgiveness}

Research has shown that forgiving a perpetrator, either within or outside of the context of religion, can be beneficial to the victim's healing process (Worthington, 2008; Worthington \& Sandage, 2016). However, in some Christian circles individuals can experience a lot of external pressure to prematurely offer forgiveness (Augsburger, 1981). I often have to give survivors of complex trauma from within these religious circles permission to not force themselves to attempt to forgive their perpetrators until they have processed their trauma. I also educate them about various types of forgiveness (Sells \& Hervey, 2011) because restoration of relationship is not always possible or even safe. In Ahmee's case, her forgiveness of the man 
who had issued the death threat appeared to be authentic and not based in denial. Ahmee had already processed the trauma associated with the death threat, as well as her fear of death. Offering forgiveness was not only therapeutic for Ahmee, but, as mentioned earlier, had positive benefits for the community at large.

\section{CULTURAL COMPLEXITIES}

Literature on multicultural counseling/therapy is much more extensive than it was when I was seeing Ahmee. I now teach courses in multicultural counseling, and I am more aware of the factors involved in being a clinician who is multiculturally competent (e.g., Sue \& Sue, 2016). Despite my concern about the limitations of therapy imposed by the brevity of my work with Ahmee, if she were a current client I would make the time to explicitly broach the topic of our cultural differences (Day-Vines et al., 2007). While I believe that our shared spiritual values compensated to some degree for this omission, there may have been aspects to Ahmee's cultural background that, had I been aware of them, could have aided our work. For example, I do not know how hierarchical the leadership in Ahmee's tribe of origin is, and how authority is understood by members of the tribe. To what extent, I wonder, did Ahmee perceive me as the "expert" in the room, thereby limiting the degree to which she felt she could disagree with my interpretations of her experience? How much did she feel she had to acquiesce to my suggestions for homework assignments or in-session interventions? Fortunately, conveying empathy is one of my clinical strengths, and my therapeutic style tends to be collaborative which hopefully mitigated my lack of knowledge about her particular culture.

Earlier, I wrote about the benefits of our shared spiritual values. Related to this, but not identical, was our shared missionary culture. When I first moved to the Philippines I was uncomfortable with the label "missionary" because as a counselor, educator and clinician, my responsibilities were much the same as they had been previously in Canada; I was just doing the work cross-culturally. However, I quickly found a sense of belonging within the missionary community. Despite differences in our particular roles and varying nationalities, we were all expatriates, struggling to adjust to a new culture, with a deep, shared sense of purpose for being there. Most missionary children attended an interdenominational school with American curriculum specifically for children of missionaries, and while most missionaries had Filipino friends and colleagues, other members of the missionary community tended to be their primary support system.

Over time I came to understand the similarities and differences among various missionary organizations. This was a result of my personal experience dealing with my institution, through casual conversation with missionaries from other agencies, and from hearing the stories of missionary clients 
who often struggled with the leadership of their organizations and/or had conflicts with team members.

Looking back, I think that because Ahmee and I were both a part of this missionary culture, the cultural and ethnic differences that existed as a result of us coming from opposite sides of the world were not of great significance to the therapeutic work. Being an insider to the missionary culture helped me to better understand some of the ongoing stressors Ahmee faced and gave me credibility both with her and the director of her mission. It also allowed the director and me to work as a team to determine how Ahmee's mission agency could help support her rather than place barriers that would impede her healing (e.g., insisting that Ahmee stay in the village for months at a time rather than allowing her the respite she needed).

The explicit discussions around culture that Ahmee and I did have were centered on the culture of the village to which Ahmee was assigned, which was very different from the broader Filipino urban culture to which I had become acculturated. I could not offer specific suggestions to Ahmee because I did not have enough knowledge about how that system worked. Exhibiting cultural humility is one of the essential tenants of doing trauma therapy across cultures (Hook, Davis, Owen, \& DeBlaere, 2017), so I asked a lot of questions in an attempt to help stimulate Ahmee's thinking about what could be helpful to her.

For example, it was clear to both Ahmee and me that she had to break the cycle of villagers waking her up multiple times a night for minor medical issues so that she would not totally burn out. How to set that boundary, though, in a culturally acceptable way that would not damage her hardwon good relationships with the villagers was a complicated issue (Monroe \& Langberg, 2017). Ahmee felt stuck, not knowing how to navigate this issue well. Her decision to consult the village elder (i.e., enlist the help of a cultural interpreter), resulting in the creative solution of his family running interference for her, was the perfect solution, but one that neither Ahmee nor I would ever have come up with ourselves.

\section{CONCLUSION}

I was unable to do long-term follow-up with Ahmee as, the last I knew, she was back in her home country waiting for the political unrest in the tribal village area to stabilize enough so that the immediate risk to her personal safety would be lessened. However, considering the degree of trauma experienced by Ahmee, I was amazed at the level of healing that apparently took place in a relatively few, irregularly-spaced sessions.

I believe a number of factors were responsible for the changes that took place. Ahmee was exceptionally well-motivated as a client and worked very hard both in and between sessions, even initiating healing strategies on her 
own (e.g., personal retreats, consultation and prayer with trusted friends and spiritual leaders). While totally isolated within the village, Ahmee made full use of an extensive support system when she was elsewhere, which is of immense help to any trauma survivor (Carlson, 1997). In the face of conflicting advice, Ahmee became more discerning, weighing what she heard from others, and trusting her own intuition. My cross-cultural experience, shared spiritual values and missionary culture, integrating spirituality into the therapy, previous work with dissociation and complex trauma survivors, and a collaborative working relationship with Ahmee's mission director, also helped.

Could a trauma therapist who was not a missionary and did not share Ahmee's religious beliefs have done good work with Ahmee? Certainly! Just as cultural humility is important in working with someone who differs from the clinician in terms of racial/ethnic diversity, cultural humility is essential in working with other aspects of cultural diversity such as spirituality (Sue \& Sue, 2016). Without humility it would likely take longer to develop rapport with Ahmee; her spirituality was so core to her that I suspect she would require time to test whether a therapist would respect her religious values and offer the freedom to incorporate spirituality into the therapeutic work. On the therapist's end, asking questions and using a lot of empathic reflection while dealing with any negative transference reactions would be essential (Verbeck et al., 2015; Young, Dowdle, \& Flowers, 2009).

For mental health professionals who are not themselves religious, dealing with the religious and spiritual issues of a client such as Ahmee could potentially feel daunting. I wonder if internally reframing spiritual issues as existential ones might help to place the clinician in more familiar territory. Benner (1998) coined the term "psychospiritual" (p. 110) by which he means that our psychological and spiritual selves are so closely intertwined that it is impossible to tease them apart. According to Benner, all existential questions are ultimately spiritual quests. This means that psychotherapists are ultimately dealing with spiritual concerns when they address such issues.

Within this framework, Ahmee's sense of living out a call from God for her to minister to the Muslim tribe in the Philippines was, in essence, a way to create a sense of existential meaning for her life (e.g., see Frankl's 1963 description of Logotherapy). Ahmee's terror at facing the potentially dangerous journey by boat, and her nightmares of being murdered, could be interpreted as symptoms of existential anxiety related to her having to face the reality of her earthly death (see May, 1950; Yalom, 2008). Dealing with the death threat by offering forgiveness to the one who made it could be viewed as a free choice Ahmee made to deal with a difficult situation, and, thereby accept responsibility for her reaction to the threat on her life (see Schneider \& Krug's 2010 discussion on the three values of existential therapy). Clinicians could choose to view their role as mental health professionals through such lenses, even while learning their clients' religious or spiritual language out of respect for their belief systems. 
I feel privileged to have worked with Ahmee. Her strength of character, authenticity, deep spirituality, resiliency, and strong motivation to do everything she could to further her healing are an ongoing inspiration in my work with trauma survivors.

\section{REFERENCES}

Association for the Spiritual, Ethical and Religious Values in Counseling (ASERVIC). (2009). ASERVIC Competencies for Addressing Spiritual and Religious Issues in Counseling. Washington, DC: American Counseling Association. Retrieved from http://www.aservic.org/resources/spiritual-competencies/

Aten, J. D., \& Leach, M. M. (Eds.). (2009). Spirituality and the therapeutic process: A comprehensive resource from intake to termination. Washington, DC: American Psychological Association.

Augsburger, D. (1981). Caring enough to forgive-Caring enough not to forgive. Ventura, CA: Regal.

Benner, D. G. (1998). Care of souls: Revisioning Christian nurture and counsel. Grand Rapids, MI: Baker Books.

Braun, B. G. (1988). The BASK model of dissociation: Clinical applications. Dissociation, 1(2), 16-23.

Brownell, P. (2015). Spiritual competency in psychotherapy. New York, NY: Springer.

Carlson, E. (1997). Trauma assessments: A clinician's guide. New York, NY: Guilford Press.

Day-Vines, N., Wood, S., Grothaus, T., Craigen, L., Holman, A., Dotson-Blake, K., \& Douglass, M. (2007). Broaching the subjects of race, ethnicity, and culture during the counseling process. Journal of Counseling \& Development, 85, 401-409.

Foa, E. B., Hembree, E. A., \& Rothbaum, B. O. (2007). Prolonged exposure therapy for PTSD: Emotional processing of traumatic experiences. New York, NY: Oxford University Press.

Frankl, V. (1963). Man's search for meaning. Boston, MA; Beacon.

Freud, S. (1950). The interpretation of dreams. New York, NY: Random House.

Garzon, F., \& Burkett, L. (2002). Healing of memories: Models, research, future directions. Journal of Psychology and Christianity, 21(1), 42-49.

Gingrich, H. D. (2013). Restoring the shattered self: A Christian counselor's guide to complex trauma. Downers Grove, IL: InterVarsity Press Academic.

Gingrich, H. D., \& Gingrich F. C. (Eds). (2017). Treating trauma in Christian counseling. Downers Grove, IL: InterVarsity Press Academic.

Harris, K. A., Randolph, B. E., \& Gordon, T. D. (2016). What do clients want? Assessing spiritual needs in counseling: A literature review. Spirituality in Clinical Practice, 3(4), 250-275. doi:10.1037/scp0000108

Hill, P. C., \& Pargament, K. I. (2008). Advances in the conceptualization and measurement of religion and spirituality: Implications for physical and mental health research. Psychology of Religion and Spirituality, S, 3-17.

Hill, P. C, Pargament, K. I., Hood, R. W., Jr., McCullough, M. E., Swyers, J. P., Larson, D. B., \& Zinnbauer, B. J. (2000). Conceptualizing religion and spirituality: Points of commonality, points of departure. Journal for the Theory of Social Behavior, 30(1), 51-77. 
Hook, J. N., Davis, D., Owen, J., \& DeBlaere, C. (2017). Cultural humility: Engaging diverse identities in therapy. Washington, DC: American Psychological Association.

Hunter, L. A. (2009). Epistemological approaches to inner healing and integration. Journal of Psychology and Christianity, 28(2), 101-104.

Hurding, R. (1995). Pathways to wholeness: Christian journeying in a postmodern age. Journal of Psychology and Christianity, 14, 293-305.

Koerner, K., \& Linehan, M. M. (2012). Doing dialectical behavior therapy: A practical guide. New York, NY: Guilford Press.

May, R. (1950). The meaning of anxiety. New York, NY: Ronald Press.

McMinn, M. (1996). Psychology, theology and spirituality in Christian counseling. Wheaton, IL: Tyndale.

Miller, W. R. (1999). (Ed.). Integrating spirituality into treatment: Resources for practitioners. Washington, DC: American Psychological Association.

Monroe, P., \& Langberg, D. (2017). Improving trauma care in developing nations: Partnerships over projects. In H. D. Gingrich \& F. C. Gingrich (Eds.), Treating trauma in Christian counseling (pp. 322-339). Downers Grove, IL: InterVarsity Press Academic.

Noricks, J. (2011). Parts psychology: A trauma-based, self-state therapy for emotional healing. Los Angeles, CA: New University Press.

Pargament, K. I. (2007). Spiritually integrated psychotherapy: Understanding and addressing the sacred. New York, NY: Guilford Press.

Plante, T. G. (2009). Spiritual practices in psychotherapy: Thirteen tools for enhancing psychological health. Washington, DC: American Psychological Association.

Presbury, J. H., Echterling, L. G., \& McKee, J. E. (2001). Ideas and tools for brief counseling. Upper Saddle River, NJ: Prentice-Hall.

Pressley, J., \& Spinazzola, J. (2015). Beyond survival: Application of a complex trauma treatment model in the Christian context. Journal of Psychology $\mathcal{E}$ Theology, 43, 8-22.

Rothbaum, F., Morelli, G., Pott, M., \& Liu-Constant, Y. (2000). Immigrant-Chinese and Euro-American parents' physical closeness with young children: Themes of family relatedness. Journal of Family Psychology, 14, 334-338.

Sbanotto, E. A. N., Gingrich, H. D., \& Gingrich, F. C. (2016). Appreciating the sacred. Skills for effective counseling: A faith-based integration. Downers Grove, IL: Intervarsity Academic.

Schneider, K. J., \& Krug, O. T. (2010). Existential-humanistic therapy. Washington, DC: American Psychological Association.

Sells, J., \& Hervey, E. G. (2011). Forgiveness in sexual abuse: Defining our identity in the journey toward wholeness. In A. J. Schmutzer (Ed.), The long journey home: Understanding and ministering to the sexually abused (pp. 169-185). Eugene, OR: Wipf \& Stock.

Shapiro, S. (2016). Easy ego-state interventions: Strategies for working with parts. New York, NY: W.W. Norton.

Siegel, D. (1999). The developing mind. New York, NY: Guilford Press.

Sue, D. W., \& Sue, D. (2016). Counseling the culturally diverse: Theory and practice ( ${ }^{\text {th }}$ ed.). New York, NY: Wiley.

Tan, S-Y. (1992). The Holy Spirit and counseling ministries. The Christian Journal of Psychology and Counseling, VII(3), 8-11. 
Verbeck, E. G., Arzoumanian, M. A., Estrellado, J. E., DeLorme, J., Dahlin, K., Hennrich, E., . . \& \& Dalenberg, C. (2015). Religion, spirituality, and the working alliance with trauma survivors. In D. F. Walker, C. A. Courtois, \& J. D. Aten (Eds.), Spiritually oriented psychotherapy for trauma (pp. 103-126). Washington, DC: American Psychological Association.

Vieten, C., \& Scammell, S. (2015). Spiritual \& religious competencies in clinical practice. Oakland, CA; New Harbinger Publications.

Vietein, C., Scammell, S., Pilato, R., Ammondson, I., Pargament, K., \& Lukoff, D. (2013). Spiritual and religious competencies for psychologists. Psychology of Religion and Spirituality, 5(3), 129-144. doi:10.1037/a0032699

Walker, D. F., Courtois, C. A., \& Aten, J. D. (Eds.). (2015). Spiritually oriented psychotherapy for trauma. Washington, DC: American Psychological Association.

Walker, D. F., McGregor, K. L., Quagliana, D., Stephens, R. L., \& Knodel, K. R. (2015). Understanding and responding to changes in spirituality and religion after traumatic events. In D. F. Walker, C. A. Courtois, \& J. D. Aten (Eds.). Spiritually oriented psychotherapy for trauma (pp. 15-28). Washington, DC: American Psychological Association.

Wiggins, M. I. (2009). Therapist self-awareness of spirituality. In J. D. Aten \& M. M. Leach (Eds.), Spirituality and the therapeutic process: A comprehensive resource from intake to termination (pp. 53-74). Washington, DC: American Psychological Association.

Worthington, E. L., Jr. (2008). Empirical research on forgiveness with Christians: What have we learned? Journal of Psychology \& Christianity, 27, 368-370.

Worthington, E. L., Jr., \& Sandage, S. J. (2016). Forgiveness and spirituality in psychotherapy: A relational approach. Washington, DC: American Psychological Association.

Yalom, I. D. (2008). Staring at the sun: Overcoming the terror of death. San Francisco, CA: Jossey-Bass.

Young, J. S., \& Cashwell, C. S. (2011). Integrating spirituality and religion into counseling: An introduction. In C. S. Cashwell (Ed.), Integrating spirituality and religion into counseling: A guide to competent practice (pp. 1-24). Alexandria, VA: American Counseling Association.

Young, J. S., Dowdle, S., \& Flowers, L. (2009). How spirituality can affect the therapeutic alliance. In J. D. Aten \& M. M. Leach (Eds.), Spirituality and the therapeutic process: A comprehensive resource from intake to termination (pp. 167-192). Washington, DC: American Psychological Association. 